studied. Poor results after surgery may be related to individual surgical technique, and Graham has reported good results in a personal series of children subjected to ileal conduit diversion. ${ }^{14}$ Moreover, although dilatation of the upper tract may arise years after operation, technical factors predisposing to ischaemia may be relevant in the aetiology of functionally important obstruction of the distal conduit. ${ }^{15}$

The incidence of bilateral upper tract dilatation noted in this study was similar to that reported in studies in children. ${ }^{1411}$ Scott commented that dilatation was not due to obvious obstruction, for many patients appeared to have wide, healthy stomas and normal loopograms. ${ }^{1}$ Ureteroileal reflux cannot of itself be the cause of dilatation, since many patients with reflux have normal upper tracts. A combination of high pressure in the conduit and reflux across the ureteroileal anastomosis may explain the dilatation.

Many children and young adults with non-malignant disease who might be considered for a urinary diversion should have a good life expectancy. It is now accepted that because of its long term morbidity diversion should be avoided whenever possible in these patients. On the other hand, because so few patients with bladder cancer will survive to develop long term side effects the use of ileal conduit diversion might be thought acceptable in them. Nevertheless, clinically important complications were observed in the patients in this study. In particular, the finding that bilateral upper tract dilatation in the absence of an obvious cause is commonplace and that it may be associated with renal damage signifies that further efforts should be made to determine its cause.
I thank Sister A Lawson, $\mathrm{Mr}$ W K Yeates, $\mathrm{Mr} \mathrm{D} M$ Essenshigh, Mr R R Hall, and Professor J Swinney, whose careful records permitted this study to be carried out. Thanks are also due to Mr R R Hall and Mr P D Ramsden for constructive criticism of the manuscript. I thank the William Leech Property Trust and the Northern Counties Kidney Research Fund for financial support.

\section{References}

1 Scott JES. Urinary diversion in children. Arch Dis Child 1973;48:199-206 Pitts WR, Muecke EC. A 20 year experience with ileal conduits: the fate of the kidneys. F Urol $1979 ; 122: 154-7$.

PJB, Slade N. The long term results of ileal conduit urinary diversion in children. Br $\mathcal{f}$ Urol $1979 ; 51: 458-61$.

Middleton AW, Hendren WH. Ileal conduits in children at the Massachuset General Hospital from 1955 to 1970 . F Urol 1976;115:591-5.

Socquet $Y$. Combined surgery and adjuvant chemotherapy with high dose methotrexate and folinic acid rescue (HDMTX-CF) for infiltrating tumour of the bladder. $\mathrm{Br} F$ Urol $1981 ; 53: 439-43$.

6 Hall RR, Newling DWW, Ramsden PD, Richards B, Robinson MRG, Smith $\mathrm{PH}$. Treatment of invasive bladder cancer by local resection and high dose

7 Wallace DM. Ureteric diversion using a conduit. A simplified technique. $\mathrm{Br} \mathfrak{F}$ Urol 1966;38:522-7.

Wallace DM. Uretero-ileostomy. Br f Urol 1970;42:529-34.

Leadbetter WF, Clarke BG. Five years' experience of uretero-enterostomy with

Payne RB. The assessment of glomerular function:

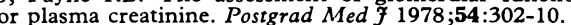
creatinine clearance or plasma creatinine. Postgrad $\mathrm{Med}$ in children: compute analysis of follow up from 2 to 16 years. $\mathcal{F}$ Urol $1975 ; 114: 285-8$.

12 Philp NH, Williams JL, Byers CE. Ileal conduit urinary diversion: long-term follow-up in adults. Br $\mathcal{F}$ Urol $1980 ; 52: 513-9$.

13 Kafetsioulis A, Swinney J. Urinary diversion by ileal conduit. A long-term

14 Graham AG. Long-term results of ileal conduit diversion in children. $\mathrm{Br} f \mathrm{Urol}$

15 McEwan AB, Clark PB. The stoma of the ileal conduit. Br $\mathcal{f}$ Urol $1973 ; 45$ :

(Accepted 28 February 1985)

\begin{abstract}
Of 17032 women taking part in the Oxford Family Planning Association contraceptive study, 4104 stopped using a birth control method to plan a pregnancy on a total of 6199 occasions. The influence of various factors on fertility in these women was assessed by measuring the time taken to give birth to a child. An appreciable inverse relation was observed between age at stopping contraception and fertility both in nulliparous and parous women, but the effect was much greater in the nulliparous women.

The most important finding was a consistent and highly significant trend of decreasing fertility with

\footnotetext{
Department of Community Medicine and General Practice, Radcliffe Infirmary, Oxford OX2 6HE

GEOFFREY HOWE, PHD, visiting professor

CAROLYN WESTHOFF, MD, Milbank scholar

MARTIN VESSEY, MD, FRCPED, professor

DAVID YEATES, PHD, computer scientist

Correspondence to: Professor M Vessey.
}

increasing numbers of cigarettes smoked per day; it was estimated that five years after stopping contraception $10.7 \%$ of smokers smoking more than 20 cigarettes a day, but only $5.4 \%$ of non-smokers, remained undelivered. Some relation was found between fertility and social class, age at marriage, and a history of gynaecological disease, but weight, height, and Quetelet's index were without noticeable effect.

\section{Introduction}

Factors that may affect a woman's fertility, such as her gynaecological and reproductive history, her age, and her smoking habit, are of both biological interest and practical concern. Opportunities to examine associations between such factors and fertility using the epidemiological approach are rare because of the lack of relevant data for adequately sized cohorts of women observed for sufficiently long periods of time during which they are known to be attempting to become pregnant. The Oxford Family Planning Association contraceptive study, which includes data on over 17000 women of childbearing age observed for an average period of about 11.5 years, provides such an opportunity. ${ }^{1}$ Oral contraceptives, and to a lesser extent intrauterine devices, have previously been reported from this study to impair fertility immediately after their discontinuation, but the effect is relatively short lived. ${ }^{2}{ }^{3}$ Here we describe the effects of various other factors on fertility in this cohort. 


\section{Subjects and methods}

The methods of the Oxford Family Planning Association contraceptive study have been described in detail elsewhere. ${ }^{1}$ In brief, 17032 white, married women, aged 25-39, were recruited at 17 family planning clinics in England and Scotland during 1968-74. At enrolment into the study each woman was interviewed and asked questions about her reproductive, medical, and social histories, including her cigarette smoking habits. During follow up visits to the clinic information is obtained on changes in contraceptive practices, including the reasons for changes, and the outcome of any pregnancies. Women who stop attending the clinics are contacted yearly by post or by telephone or are visited at home, and as a consequence the annual rate of loss to follow up for reasons other than emigration or death is only of the order of $0.3 \%$.

Here we consider fertility through to October 1983 in the 4104 women who stopped contraception to become pregnant after enrolling in the study. Some of these women stopped contraception to become pregnant more than once; in all, 6199 episodes-that is, periods at risk of becoming pregnant-were included in the analysis. These episodes were treated as if they were all independent, which clearly is not strictly correct. Additional analyses have, however, been undertaken in which only the first episode was considered for each woman; the findings were virtually identical to those reported here.

As data were not available on the date of the last menstrual period before a pregnancy occurred we assessed fertility by measuring the time taken to give birth to a child, as had been done in previous analyses. ${ }^{2} 3 \mathrm{We}$ did, however, carry out additional analyses using an estimated date of last menstrual period, which also took account of any type of pregnancy outcome-that is, not just live births and still births - and obtained essentially similar results to those described below.

During the analysis the number of women under observation and the number of successful outcomes were classified by months elapsed since stopping contraception to become pregnant and by categories of explanatory variables. Women left the analysis when they resumed contraception, were lost to follow up, or reached the closure date (October 1983). For each variable women at one level were chosen as the reference group, and, relative to that level, risks for the other levels were estimated. We called these relative risks relative fertility rates. The relative fertility rate was estimated for each month of follow up during which at least 10 women remained undelivered in both the groups being compared. None of the relative fertility rates showed any important heterogeneity between months (although, of course, the base fertility rate did); accordingly, a pooled relative fertility rate was calculated for each level of each factor, using the methods proposed by Mantel and Haenszel. ${ }^{4}$ This relative fertility rate may be interpreted as the relative increase or decrease in the fertility rate experienced during every month of the follow up period. For example, a relative fertility rate of 1.1 would imply that, on average, women in the group concerned would experience $10 \%$ more successful outcomes each month than the women in the reference group. Tests for trend in relative fertility rates were carried out using the Mantel procedure. ${ }^{5}$ All $\mathrm{p}$ values quoted are two tailed. The effect on fertility of the method of contraception stopped has been reported previously ${ }^{2}{ }^{3}$ and so is not included in this paper, although contraceptive method was taken into account as a confounding variable when appropriate.

\section{Results}

None of the variables height, weight, or Quetelet's index (weight/ height squared) showed significant or consistent associations with fertility. The 808 women with a history of miscarriage or termination of pregnancy had a slightly increased relative fertility rate of 1.08 ( $95 \%$ confidence interval 0.99-1 18). Conversely, the 368 women who had a history of major menstrual disorders, dilatation and curettage, or other reported gynaecological problems had decreased relative fertility rates of $0.9,0.86$, and 0.89 , respectively. Only the last of these was significant, and the small number of women in each of the groups precluded further analysis.

Table I shows other variables considered in the analysis. All had significant effects on fertility. A certain amount of confounding was found to exist among the variables, which necessitated the adjustments shown in table I. No evidence of other important confounding was found; when an analysis including all the variables simultaneously in a proportional hazards regression model ${ }^{6}$ was performed the relative fertility rates set out in table I were confirmed with if anything the emergence of even stronger trends.
A trend of decreasing fertility with decreasing social class was observed, although the reduction was not large and the estimate for social classes IV-VI was based on fairly small numbers. Adjustment of the social class relative fertility rates for the effects of smoking and parity had little effect, the influence of these two variables being in opposite directions. Table I shows unadjusted relative fertility rates. Women who married at age 20 or more had a significantly

TABLE I-Relative fertility rates in the Oxford Family Planning Association contraceptive study classified by various factors

\begin{tabular}{|c|c|c|c|}
\hline Factor & $\begin{array}{l}\text { No of } \\
\text { episodes of } \\
\text { attempting } \\
\text { pregnancy }\end{array}$ & $\begin{array}{l}\text { Months } \\
\text { of } \\
\text { follow } \\
\text { up* }\end{array}$ & $\begin{array}{c}\text { Relative fertility } \\
\text { rate } \\
(95 \% \text { confidence } \\
\text { interval })\end{array}$ \\
\hline $\begin{array}{l}\text { Social class of husbandt: } \\
\text { I } \\
\text { II } \\
\text { III } \\
\text { IV-VI§ }\end{array}$ & $\begin{array}{r}1378 \\
1920 \\
2545 \\
351\end{array}$ & $\begin{array}{r}115 \\
115 \\
115 \\
66\end{array}$ & $\begin{array}{l}1.0 \ddagger \\
0.96(0.90-1.03) \\
0.90(0.84-0.96) \\
0.91(0.81-1.03) \\
\text { p (trend) } 0.0005\end{array}$ \\
\hline $\begin{array}{l}\text { Age at marriage (years) } \|: \\
<20 \\
20-24 \\
25-29 \\
\geqslant 30\end{array}$ & $\begin{array}{r}433 \\
4062 \\
1583 \\
116\end{array}$ & $\begin{array}{l}91 \\
91 \\
91 \\
43\end{array}$ & $\begin{array}{l}1.0 \pm \\
1.27(1 \cdot 14-1 \cdot 41) \\
1.24(1.09-1 \cdot 41) \\
1 \cdot 06(0.83-1.35) \\
p \text { (trend) } 0.2656\end{array}$ \\
\hline $\begin{array}{l}\text { Parity (No of previous live or still } \\
\quad \text { births) } \\
0 \\
1 \\
2 \\
2 \geqslant 3\end{array}$ & $\begin{array}{r}2484 \\
2628 \\
810 \\
272\end{array}$ & $\begin{array}{r}138 \\
124 \\
67 \\
54\end{array}$ & $\begin{array}{l}1.0 \pm \\
1.44(1.36-1.52) \\
1.73(1.58-1.90) \\
1.86(1.58-2 \cdot 20) \\
\text { p (trend) }<0.0001\end{array}$ \\
\hline $\begin{array}{l}\text { Age, nulliparous women (years)**: } \\
25-27 \\
28-29 \\
30-31 \\
32-33 \\
34-35 \\
36-37 \\
38-39 \\
\geqslant 40\end{array}$ & $\begin{array}{r}1076 \\
691 \\
377 \\
181 \\
102 \\
43 \\
7 \\
7\end{array}$ & $\begin{array}{r}130 \\
128 \\
91 \\
58 \\
51 \\
23\end{array}$ & $\begin{array}{l}1.0 \ddagger \\
0.92(0.83-1.01) \\
0.79(0.70-0.90) \\
0.75(0.64-0.89) \\
0.55(0.43-0.71) \\
0.48(0.31-0.73) \\
p(\text { trend })<0.0001\end{array}$ \\
\hline $\begin{array}{l}\text { Age, parous women (years)**: } \\
25-27 \\
28-29 \\
30-31 \\
32-33 \\
34-35 \\
36-37 \\
38-39 \\
\geqslant 40\end{array}$ & $\begin{array}{r}599 \\
874 \\
856 \\
648 \\
413 \\
181 \\
95 \\
44\end{array}$ & $\begin{array}{l}56 \\
56 \\
56 \\
56 \\
53 \\
24 \\
32 \\
21\end{array}$ & $\begin{array}{l}1.0 \ddagger \\
1.09(0.99-1.21) \\
1.00(0.90-1.11) \\
0.90(0.80-1.01) \\
0.86(0.74-0.99) \\
0.97(0.80-1 \cdot 19) \\
0.64(0.48-0.86) \\
0.49(0.30-0.81) \\
\text { p (trend) }<0.0001\end{array}$ \\
\hline $\begin{array}{l}\text { Cigarette smoking (No/day)**: } \\
\text { Never smoked } \\
\text { Ex-smoker } \\
1-5 \\
6-10 \\
11-15 \\
16-20 \\
\geqslant 21\end{array}$ & $\begin{array}{r}3672 \\
843 \\
389 \\
485 \\
374 \\
334 \\
97\end{array}$ & $\begin{array}{r}134 \\
111 \\
54 \\
94 \\
105 \\
93 \\
29\end{array}$ & $\begin{array}{l}1.0+ \\
0.99(0.92-1.07) \\
1.00(0.90-1 \cdot 11) \\
0.97(0.88-1.07) \\
0.93(0.84-1.04) \\
0.79(0.70-0.89) \\
0.78(0.62-0.97) \\
\text { p (trend) }<0.0001\end{array}$ \\
\hline
\end{tabular}

*Number of months for which at least 10 women remained at risk in both reference

and risk groups.

†Registrar Generals

$\$$ ¿lass VI includes armed forces, students, and unemployed.

Adjusted for parity.

Adjusted for age at stopping contraception.

**Adjusted for method stopped.

increased fertility rate relative to those who married before the age of 20, but this effect was barely apparent among the few who married over the age of 29 . Parity was strongly associated with fertility rates, women of parity three or more experiencing almost twice as high a relative fertility rate as nulliparous women. The age at which contraception was stopped to become pregnant also had a strong influence on fertility. For parous women the effect was modest until age 37, but for nulliparas there was a noticeable decrement in every age group shown in table I.

Finally, there was a consistent and highly significant trend of decreasing fertility with increasing number of cigarettes smoked per day. The data refer to smoking habits at the time of entering the study (the only smoking data currently available for the cohort) rather than at the time of stopping contraception. Ex-smokers did not show any evidence of a decrease in fertility relative to lifetime nonsmokers.

To illustrate the practical consequences of the relative fertility rates shown in table $I$ the probability of a woman remaining undelivered over a period of years was estimated for various subgroups using the relative fertility rates in conjunction with standard life table techniques. Tables II and III show the results for smoking and age at stopping contraception. Evidence for the validity of these 
TABLE II-Estimated proportions (\%) of women remaining undelivered of a live or still birth by smoking habit

\begin{tabular}{|c|c|c|c|c|c|c|}
\hline \multirow{2}{*}{$\begin{array}{l}\text { Cigarettes } \\
\text { smoked } \\
\text { per day }\end{array}$} & \multicolumn{6}{|c|}{ Months after stopping contraception } \\
\hline & 12 & 18 & 24 & 36 & 48 & 60 \\
\hline $\begin{array}{l}\text { Never smoked } \\
\text { Ex-smoker } \\
1-5 \\
6-10 \\
11-15 \\
16-20 \\
\geqslant 21\end{array}$ & $\begin{array}{l}41 \cdot 0 \\
41 \cdot 3 \\
41 \cdot 1 \\
42 \cdot 3 \\
43 \cdot 8 \\
50 \cdot 4 \\
50.9\end{array}$ & $\begin{array}{l}18 \cdot 7 \\
19 \cdot 0 \\
18 \cdot 8 \\
19 \cdot 8 \\
21 \cdot 1 \\
27 \cdot 4 \\
27 \cdot 9\end{array}$ & $\begin{array}{l}12.5 \\
12.8 \\
12.6 \\
13.5 \\
14.5 \\
20 \cdot 0 \\
20.5\end{array}$ & $\begin{array}{r}7 \cdot 8 \\
8 \cdot 0 \\
7 \cdot 9 \\
8 \cdot 5 \\
9 \cdot 3 \\
13 \cdot 8 \\
14 \cdot 2\end{array}$ & $\begin{array}{r}6 \cdot 2 \\
6.3 \\
6 \cdot 2 \\
6 \cdot 8 \\
7.5 \\
11.5 \\
11.9\end{array}$ & $\begin{array}{r}5 \cdot 4 \\
5 \cdot 5 \\
5 \cdot 4 \\
6 \cdot 0 \\
6 \cdot 6 \\
10 \cdot 4 \\
10 \cdot 7\end{array}$ \\
\hline
\end{tabular}

TABLE III-Estimated proportions ( $\%$ ) of nulliparous and parous women remaining undelivered of a live or still birth by age at stopping contraception

\begin{tabular}{|c|c|c|c|c|c|c|}
\hline \multirow{2}{*}{$\begin{array}{l}\text { Age at stopping } \\
\text { contraception } \\
\text { (years) }\end{array}$} & \multicolumn{6}{|c|}{ Months after stopping contraception } \\
\hline & 12 & 18 & 24 & 36 & 48 & 60 \\
\hline \multicolumn{7}{|c|}{ Nulliparous women } \\
\hline $\begin{array}{l}25-27 \\
28-29 \\
30-31 \\
32-33 \\
34-35 \\
36-37\end{array}$ & $\begin{array}{l}50 \cdot 3 \\
53 \cdot 6 \\
58 \cdot 6 \\
60 \cdot 3 \\
69 \cdot 6 \\
73 \cdot 1\end{array}$ & $\begin{array}{l}23 \cdot 1 \\
26 \cdot 3 \\
31 \cdot 9 \\
33 \cdot 8 \\
45 \cdot 9 \\
51 \cdot 0\end{array}$ & $\begin{array}{l}14 \cdot 4 \\
17 \cdot 1 \\
22 \cdot 0 \\
23.8 \\
35 \cdot 6 \\
41 \cdot 0\end{array}$ & $\begin{array}{r}9 \cdot 8 \\
12 \cdot 0 \\
16 \cdot 2 \\
17 \cdot 8 \\
28 \cdot 8 \\
37 \cdot 1\end{array}$ & $\begin{array}{r}7 \cdot 3 \\
9 \cdot 2 \\
12 \cdot 8 \\
19 \cdot 3 \\
24 \cdot 5 \\
29 \cdot 6\end{array}$ & $\begin{array}{r}5 \cdot 9 \\
7.5 \\
10 \cdot 8 \\
12 \cdot 2 \\
21 \cdot 8 \\
26 \cdot 8\end{array}$ \\
\hline \multicolumn{7}{|c|}{ Parous women } \\
\hline $\begin{array}{l}25-27 \\
28-29 \\
30-31 \\
32-33 \\
34-35 \\
36-37 \\
38-39 \\
40+\end{array}$ & $\begin{array}{l}38 \cdot 7 \\
34 \cdot 9 \\
38 \cdot 8 \\
43 \cdot 0 \\
45 \cdot 0 \\
39 \cdot 7 \\
55 \cdot 9 \\
64 \cdot 5\end{array}$ & $\begin{array}{l}14 \cdot 7 \\
12 \cdot 0 \\
14 \cdot 7 \\
18 \cdot 1 \\
19 \cdot 8 \\
15 \cdot 5 \\
30 \cdot 6 \\
40 \cdot 9\end{array}$ & $\begin{array}{r}8.5 \\
6.6 \\
8.6 \\
11 \cdot 1 \\
12.5 \\
9.1 \\
21.8 \\
31.6\end{array}$ & $\begin{array}{r}4 \cdot 2 \\
3 \cdot 0 \\
4 \cdot 2 \\
5 \cdot 9 \\
6 \cdot 8 \\
4 \cdot 6 \\
13 \cdot 9 \\
22 \cdot 5\end{array}$ & $\begin{array}{r}2 \cdot 8 \\
1.9 \\
2 \cdot 8 \\
4 \cdot 1 \\
4 \cdot 8 \\
3 \cdot 1 \\
10 \cdot 8 \\
18.5\end{array}$ & $\begin{array}{r}2 \cdot 5 \\
1.8 \\
2.6 \\
3 \cdot 8 \\
4.5 \\
2 \cdot 8 \\
10 \cdot 1 \\
17.7\end{array}$ \\
\hline
\end{tabular}

probabilities exists for the number of months for which there are adequate follow up data (as given in table I). As stated previously, no evidence was found of changes in the relative fertility rates during the periods under observation, and therefore it seems reasonable to extrapolate them over the intervals shown.

\section{Discussion}

The data presented here show that various personal characteristics are significantly associated with fertility rates after stopping contraception. The findings are indicative of the power of the Oxford Family Planning Association study to detect significant differences even when such differences are small.

The variable of social class showed a small but highly significant effect on fertility rates. The observed decrement is not explained by any of the other factors included in the present analysis. The apparently decreased fertility of women who married before the age of 20 was probably a consequence of the study design: women were recruited to the investigation only after age 25 , by which age $90 \%$ of those who had married before age 20 had already completed their families. The $10 \%$ who had not completed their families after five or more years of marriage probably included an appreciable proportion of subfertile women.

The strong association between parity and fertility was to be expected. Parous women have already proved their fertility, but among those who are nulliparous there will inevitably be some unsuspected sterile women (or women with sterile husbands) whose inclusion in the group will depress the relative fertility rate. Similarly, women of a given age who have already borne two children are likely to be more fertile on average than women of the same age who have borne only one child. Selective effects such as these cannot be distinguished from any direct biological influence of pregnancy (such as a modification of the uterine or hormonal milieu) on subsequent fertility; such influences, if they exist, could be in either, or both, direction.

The small increase in fertility seen among women experiencing a previous termination or miscarriage may similarly be interpreted as a selective effect; that the relative fertility rate was lower than that for parous women suggests that this effect is partially negated by the tendency to miscarry again among those who have previously miscarried. It should be noted that the combined effect of miscarriages and terminations was dominated by miscarriages as terminations represented only a small proportion of such events in this study.

We observed an appreciable inverse relation between age at stopping contraception and fertility for both nulliparous and parous women. This relation has been observed previously in small and unusual groups of women when the applicability of the findings to the general population has been questioned. ${ }^{7} 8$ We believe the experience of women in the Oxford Family Planning Association contraceptive study to be more, although not completely, generally applicable.

The effect of age on fertility is unlikely for several reasons to have been due solely to a deterioration in ovarian function. The group of women attempting to become pregnant at an older age was likely to have included some who had failed to achieve their desired family size while younger. In fact, three quarters of the women recruited in the Oxford study stated that they had already completed their families at the time of enrolment, and during the study over 1500 unplanned pregnancies occurred despite the generally consistent use of effective contraceptive methods. Many of these earlier pregnancies would have had the effect of removing the more fertile women from the group that would plan first or further pregnancies at an older age. Furthermore, pregnancy rates are directly related to coital frequency, and coital frequency declines with age and duration of marriage. ${ }^{9}$ Although we have no direct information in this study about coital frequency, it seems reasonable to suppose that this factor contributed to the observed decrease in relative fertility rates with age. A higher incidence of miscarriage contributed appreciably to lower fertility only among women aged 40 years or older.

The relation between age and fertility was different for nulliparous and parous women. The pattern of fertility seen in the parous women-modest decreases in fertility up to the age of 37 followed by a large decrease among those aged 38 or more-is acceptably explained by changes in ovarian function with age; among the nulliparous women, however, a significant decrease in fertility occurred gradually and relentlessly from age 28 onward. This finding must, at least in part, be attributable to more powerful selective influences operating on nulliparous women than on parous women.

The newest and most important finding in the present study relates to the effect of smoking on fertility. We have been able to find only one other publication on this topic: Olsen et al reporting a delay in conception among smokers in a case-control study conducted in Denmark. ${ }^{10}$ In our investigation impairment of fertility among heavy smokers was substantial, as may be seen in tables I and II. As information on cigarette smoking at the time of stopping contraception to become pregnant was not available in our study substantial misclassification undoubtedly took place. Such misclassification would lead to underestimation of the decrease in fertility attributable to smoking as study subjects are more likely to have reduced or given up smoking (particularly users of oral contraceptives) than to have increased it and as ex-smokers do not appear to suffer a reduction in fertility. In the Oxford Family Planning Association study cigarette smoking has been related to an increased incidence of pelvic inflammatory disease; this disease among the study participants was, however, uncommon, ${ }^{11}$ and the association does not explain the decreased relative fertility rates observed in heavy smokers. No appreciable increase was seen in the incidence of miscarriages among smokers in our study. The dose response relation between smoking and the relative fertility rates certainly suggests a causal relation. Smoking has been associated with an altered urinary oestrogenic profile during the menstrual cycle $^{12}$ and with an earlier age at natural menopause ${ }^{13}$; perhaps smoking affects fertility through an effect on the hormonal milieu. Any indirect influence-for example, women who smoke having husbands with similar habits whose smoking affects spermatogenesis-would be unlikely to produce such a strong 
and consistent effect. It seems reasonable therefore, in view of the evidence we have presented, to advocate that women should reduce their cigarette consumption or stop smoking not only during pregnancy but also when they are attempting to become pregnant.

We thank Patricia Brown, Claire Henry, Melanie Lawless, and the research assistants, doctors, nurses, and administrative staff working in the clinics for their hard work and loyal support. We received helpful advice and comments from Dr W H James and Dr D Coleman. The Oxford Family Planning Association contraceptive study is funded by the Medical Research Council. During this project Professor Howe was in receipt of an Eleanor Roosevelt International Cancer Fellowship of the American Cancer Society and Dr Westhoff was supported by the Milbank Scholar Program.

\section{References}

1 Vessey M, Doll R, Peto R, Johnson B, Wiggins P. A long-term follow-up study of women using different methods of contraception-an interim report. f Biosoc Sci 1976;8:373-427.
2 Vessey $M$, Wright $\mathrm{N}, \mathrm{McPherson} \mathrm{K}$, Wiggins $\mathrm{P}$. Fertility after stopping different methods of contraception. Br Med f $1978 ; \mathrm{i}: 265-7$.

3 Vessey $M$, Lawless $M$, McPherson K, Yeates D. Fertility after stopping use of intrauterine contraceptive device. $B r$ Med $f$ 1983;286:106.

4 Mantel N, Haenszel W. Statistical aspects of the analysis of data from retrospective studies of disease. Fournal of the National Cancer Institute 1959;22:

5 Mantel N. Chi-square tests with one degree of freedom; extensions of the Mantel-Haenszel procedure. $\mathcal{F} A M A$ 1969;58:690-700.

Breslow $\mathrm{T}$. Analysis of survival data under the proportional hazards model. International Statistical Review 1975;43:45-58.

7 Fédération CECOS, Schwartz D, Mayaux MJ. Female fecundity as a function of age. Results of artificial insemination in 2193 nulliparous women with azoospermic husbands. $N$ Engl $\mathcal{F}$ Med 1982;307:404-6.

8 Tietze C. Reproductive span and rate of reproduction among Hutterite women. Fertil Steril $1957 ; 8: 89-97$.

9 James WH. The causes of the decline in fecundability with age. Soc Biol 1979; $26: 330-4$.

10 Olsen J, Rachootin P, Schiodt AV, Damsbo N. Tobacco use, alcohol consumption and infertility. Int $f$ Epidemiol $1983 ; 12: 179-84$.

11 Vessey $M$, Yeates D, Flavel R, McPherson K. Pelvic inflammatory disease and the intrauterine device: findings in a large cohort study. $B r$ Med $f 1981 ; 282$ : $855-7$.

12 MacMahon B, Trichopoulos D, Cole P, Brown J. Cigarette smoking and urinary estrogens. N Engl F Med 1982;307:1062-5.

13 Jick H, Porter J, Morrison AS. Relation between smoking and age of natural menopause. Lancet 1977; i:1354-5.

(Accepted 28 February 1985)

\title{
Abnormalities in vascular arachidonic acid metabolism in the infant of the diabetic mother
}

\author{
MARIE J STUART，SHIRAZALI G SUNDERJI， RONALD W WALENGA， B N YAMAJA SETTY
}

\begin{abstract}
The infant of the diabetic mother has an increased incidence of thromboses in utero and in the neonatal period. In the adult with diabetes a decrease in prostacyclin formation has been suggested as a cause for the atherothrombotic tendency. We therefore evaluated arachidonic acid metabolism in infants of diabetic mothers. Endogenous radioimmunoassayable 6-keto prostaglandin $F_{1 \alpha}\left(P G_{1 \alpha}\right)$ was normal in umbilical vessels obtained from the infants of diabetic mothers whose glucose homoeostasis was maintained when compared with control values. Nevertheless, a significant inhibition of vascular production of 6-keto PGF $_{1^{\alpha}}$ was observed in infants born to mothers with raised $\mathbf{H b A}_{1 \mathrm{c}}$ concentrations. $A$ decrease in the concentration of plasma 6-keto $P G_{1^{\alpha}}$ was also seen in the infants of diabetic mothers when compared with control neonates.

The correlation observed between plasma 6-keto PGF $_{1^{\alpha}}$ concentrations and endogenous vascular prostacyclin formation in the infants of diabetic mothers indicates that the in vitro deficiency of prostacyclin formation reflects a concomitant in vivo abnormality.
\end{abstract}

Departments of Paediatrics and Obstetrics and Gynaecology, State University of New York, Upstate Medical Center, Syracuse NY 13210, USA

MARIE J STUART, MD, professor of paediatrics and research professor of obstetrics and gynaecology

SHIRAZALI G SUNDERJI, MD, associate professor of obstetrics and gynaecology

RONALD W WALENGA, assistant professor, department of paediatrics

B N YAMAJA SETTY, PHD, research associate, department of paediatrics

Correspondence and requests for reprints to: Professor Marie J Stuart.
Moreover, since prostacyclin functions as an endogenous pulmonary vasodilator, a decrease in plasma concentrations might contribute to the transient respiratory distress observed in infants of diabetic mothers.

\section{Introduction}

Abnormalities in the production of platelet thromboxane and vascular prostacyclin have been implicated in the atherothrombotic tendency observed in diabetes mellitus in both humans and animals. ${ }^{1-4}$ The infant of the diabetic mother is recognised as showing an increased incidence of thromboses and thromboembolic phenomena both in utero and in the immediate neonatal period. ${ }^{5}$ The pathogenesis of this complication in infants of diabetic mothers, however, has not been extensively investigated. Our study was designed to evaluate vascular arachidonic acid metabolism in the infant of the diabetic mother. Methods included both radioimmunoassays for 6-keto prostaglandin $\mathrm{F}_{1^{\alpha}}\left(\mathrm{PGF}_{1 \alpha}\right)$ (the stable end product of prostacyclin), and the use of a radioactive precursor to assess possible changes in the pattern of vascular arachidonate metabolism.

\section{Subjects and methods}

The study was performed in two parts. Initially, for the assessment of vascular arachidonic acid metabolism, umbilical cords were obtained from 15 control infants and from 17 infants of comparable gestational age born to diabetic mothers at the time of delivery by caesarean section. Classification of maternal diabetes was established according to standard criteria and included class $A(n=4)$, class $B$ $(n=8)$, class $C(n=3)$, class $D(n=1)$, class $R(n=1)$. No control or diabetic mother smoked or had taken aspirin within two weeks of delivery. Maternal blood samples were evaluated for fasting blood glucose concentrations and for glycosylated haemoglobin $\left(\mathrm{HbA}_{1 \mathrm{c}}\right)$ before delivery. ${ }^{6}$ The umbilical cords were dissected, the umbilical 